Research Report

\title{
PREVALENCE AND FACTORS ASSOCIATED WITH POST- TRAUMATIC STRESS DISORDER AMONG FLOOD-AFFECTED ADULTS IN A PANCHAYAT IN ERNAKULAM DISTRICT IN KERALA
}

\author{
Vinu Cherian ${ }^{1}$, Joel Philip², Alexander John ${ }^{1 *}$ \\ ${ }^{1}$ Department of Community Medicine, Sree Narayana Institute of Medical Sciences, Ernakulam \\ ${ }^{2}$ Peejays Neuro centre, Ayesha Road, Vyttila, Kochi \\ Corresponding address: Department of Community Medicine, Sree Narayana Institute of Medical Sciences, Chalakka, \\ Ernakulam-683594, Email: alexanderjohn.snims@gmail.com
}

\section{ABSTRACT}

Background: Floods affected the state of Kerala following unusually heavy rainfall during the monsoon season in August 2018. Post-Traumatic Stress Disorder (PTSD) is the most common and debilitating psychological disorder among victims of floods or any other massive disaster. This study aimed to determine the prevalence and the factors associated with Post-Traumatic Stress Disorder (PTSD) among flood-affected adults in a panchayat in Kerala. In light of the looming threat of climate change, and with Kerala being especially prone to recurring floods due to its geographical location, there is an urgent need to assess the impact of floods on the psychological wellbeing of the residents of the state. To the best of our knowledge, this is the first study to investigate the occurrence of PTSD among the residents of Kerala following exposure to floods. Methods: This was a cross-sectional study undertaken in 100 households in a flood-affected community in Kerala. The PTSD Checklist for DSM-5 (PCL-5) was administered to diagnose PTSD. The intensity of flood exposure was measured using a checklist of ten factors. Results: The prevalence of PTSD was 22\%. Loss of a relative, physical injury, and affliction with a physical illness were significantly associated with PTSD. A higher intensity of flood exposure was associated with a greater prevalence of PTSD. Conclusion: Our study demonstrates the high prevalence of PTSD following floods in Kerala and the need to conduct post-disaster mental health screening. It highlights those factors that may predict the occurrence of PTSD in the affected population. Recommendations are also put forward to mitigate the psychological impact of floods on the inhabitants of the state in the coming years.

Keywords: flood, Kerala, post-traumatic stress disorder

\section{INTRODUCTION}

A disaster is a severe disruption-psychological, and psychosocial-which the affected community is unable to cope with. Survivors of a disaster invariably sustain one or the other form of emotional trauma. ${ }^{1}$

Post-Traumatic Stress Disorder (PTSD) is probably the most common and debilitating psychological

\begin{tabular}{|l|c|}
\hline Access the article online: & QR Code \\
https://kjponline.com/index.php/kjp/article/view/222 & \\
DOI: https://doi.org/10.30834/KJP.33.2.2020.222 & Received: 28/10/2020. Web publication: 6/12/2020 \\
\hline
\end{tabular}

disorder among victims of floods or any other massive disaster. ${ }^{2}$ The diagnosis of PTSD requires exposure to a traumatic and stressful event that the person experienced, witnessed, or confronted, with actual or threatened death or serious injury or threat to the physical integrity of oneself or a significant other. The traumatic event is persistently re-experienced in the

\footnotetext{
How to cite the article: Cherian V, Philip J, John A. Prevalence and factors associated with post-traumatic stress disorder among flood-affected adults in a panchayat in Ernakulam district in Kerala. Kerala Journal of Psychiatry 2020, 33(2):
} 
form of nightmares, flashbacks, and emotional distress after exposure to reminders of the event in question. The person attempts to avoid any stimuli related to the trauma. There may be affective disturbances in terms of depressive cognitions and negative thoughts and feelings. Hypervigilance and a heightened startle reaction are also commonly seen, with several of these symptoms having to last for more than a month to make a definitive diagnosis. Persons who have PTSD often have co-morbid depression, which can have a disabling effect on their day-to-day lives. Most importantly, a person who has PTSD is at a higher risk for suicide and intentional self-harm. ${ }^{3}$

The floods that ravaged Kerala in August 2018 claimed 453 lives and nearly 140 people went missing. Over 14.5 lakh people were forced to relocate to more than 3000 relief camps. The state reported damages worth 31000 crore rupees due to this calamity. ${ }^{4} \mathrm{~W}$ ith climate change becoming an undeniable reality, populations in certain regions of the world are becoming more prone to recurrent exposures to natural disasters. The inhabitants of coastal Kerala represent one such at-risk population. There is an urgent need to assess the impact of such events on the psychological wellbeing of those who are afflicted, to mitigate its effects in the years to come.

The objectives of the study were to determine the prevalence and the factors associated with PTSD among flood-affected adults in a rural population of Kerala. To the best of our knowledge, this is the first study to report the occurrence of PTSD among the residents of Kerala following exposure to floods.

\section{MATERIALS AND METHODS}

Ours was a cross-sectional study conducted in September 2019 in the flood-affected panchayat of Kunnukara in Ernakulam district in Kerala. The approval for this research work was obtained from the Institutional Research and Ethical Committee before initiating the study. Kunnukara panchayat covers an approximate area of 12.6 square kilometres that is divided into 15 wards. This area was selected because its inhabitants had borne the brunt of floods in 2018, following the overflowing of the Chalakudy and the Periyar rivers. Two wards (numbers 13 and 14) were randomly selected as sites for the study. The lottery system was used for random selection. A list of all the households in the panchayat was obtained from the local panchayat office, and simple random sampling was done, wherein houses were randomly selected to obtain the requisite sample. Adults aged 18 years and older who were residents of Kunnukara Panchayat for at least one year and gave written informed consent to be a part of the study were interviewed, with one adult being chosen from each household using the age-order method. Those persons who reported having a previously diagnosed psychiatric condition were excluded from the sample.

Sample size was estimated using the formula $n=4 p q / d^{2}$ where, $p=$ known prevalence of the disease, $q=1-p$, and $d=$ absolute error. The prevalence of PTSD was observed to be $51.3 \%$ among flood-affected individuals in a study conducted by Ashok $\mathrm{V}$ et al. in the neighbouring state of Tamil Nadu. ${ }^{5}$ By assigning this value to the variable ' $\mathrm{p}$ ', and considering an absolute error of $10 \%$, a sample size of 99.9 was obtained which was rounded off to 100 individuals.

The study participants were interviewed using a semistructured questionnaire that was administered in the local vernacular. Socio-demographic data that was collected included age, sex, education, occupation, income, marital status, type of dwelling, and presence of any chronic diseases in the respondent.

The Malayalam translation of the Post-traumatic Stress Disorder Checklist for DSM-5 (PCL-5) questionnaire was administered to diagnose PTSD in the respondents. The scale consists of 20 items with five responses (0-4) that assess the presence and severity of PTSD symptoms. The total score ranges from 0 to 80 . A score of 33 or greater would mean that the respondent has met the criteria for PTSD. ${ }^{6}$ The PCL-5 has been demonstrated to be a psychometrically sound measure of PTSD symptoms, in previous studies done both in India and abroad. ${ }^{7,8}$

According to previous studies, ten factors were assessed to measure the intensity of flood exposure in the study subjects. ${ }^{9}$ These factors were the loss of a relative, loss of property, damage to one's house, financial loss, loss of livelihood, bodily injury, loss of livestock, displacement from home, physical illness, and involvement in rescue services. A respondent was determined to have a high intensity of flood-exposure if they answered 'yes' to a certain number of questions equal to or greater than the median of the number of 
Table 1. Association of socio-demographic characteristics with PTSD in the study population

\begin{tabular}{|c|c|c|c|c|c|}
\hline Characteristics & & $\begin{array}{l}\text { PTSD } \\
\text { present }\end{array}$ & $\begin{array}{l}\text { PTSD } \\
\text { absent }\end{array}$ & $\begin{array}{l}\text { Chi-square } \\
\text { value }\end{array}$ & (p-value) \\
\hline \multirow{2}{*}{ Age } & $<50$ years & $4(18.1 \%)$ & $46(59 \%)$ & \multirow{2}{*}{ _*** } & \multirow{2}{*}{$0.001^{* *}$} \\
\hline & $>50$ years & $18(81.9 \%)$ & $32(41 \%)$ & & \\
\hline \multirow{2}{*}{ Gender } & Males & $3(13.6 \%)$ & $26(33.3 \%)$ & \multirow{2}{*}{-*** } & \multirow{2}{*}{0.095} \\
\hline & Females & $19(86.4 \%)$ & $52(66.7 \%)$ & & \\
\hline \multirow{2}{*}{ Education } & Up to primary school & $14(63.6 \%)$ & $29(37.2 \%)$ & \multirow{2}{*}{3.93} & \multirow{2}{*}{$0.048^{* *}$} \\
\hline & More than primary school & $8(36.3 \%)$ & $49(62.8 \%)$ & & \\
\hline \multirow{3}{*}{$\begin{array}{l}\text { Occupation of the head of } \\
\text { the family }\end{array}$} & Unskilled & $13(59.1 \%)$ & $38(48.7 \%)$ & \multirow{3}{*}{2.62} & \multirow{3}{*}{0.454} \\
\hline & Skilled & $6(27.3 \%)$ & $31(39.7 \%)$ & & \\
\hline & Unemployed & $3(13.6 \%)$ & $9(11.6 \%)$ & & \\
\hline \multirow{2}{*}{$\begin{array}{l}\text { The vulnerable group in the } \\
\text { family* }\end{array}$} & Present & $12(54.5 \%)$ & $39(50 \%)$ & \multirow{2}{*}{0.40} & \multirow{2}{*}{0.526} \\
\hline & Absent & $10(45.5 \%)$ & $39(50 \%)$ & & \\
\hline \multirow{2}{*}{ Chronic disease } & Present & $11(50 \%)$ & $32(41 \%)$ & \multirow{2}{*}{0.95} & \multirow{2}{*}{0.329} \\
\hline & Absent & $11(50 \%)$ & $46(59 \%)$ & & \\
\hline
\end{tabular}

questions answered 'yes' in the study population. In our study population, as the median value of the number of questions receiving an affirmative response was determined to be six, those respondents who answered 'yes' to six or more questions were determined to have a high intensity of flood exposure. Similarly, an exposure characterized by an affirmative response to less than six variables was categorized as being of low intensity. The data was entered in MS Excel and analyzed using SPSS 20 software. Chi-square test and Fisher's exact test were used to analyze the association between the sociodemographic variables, the intensity of flood exposure, and PTSD.

\section{RESULTS}

Twenty-two per cent of persons surveyed reported symptoms of PTSD. The socio-demographic details of the study sample are elaborated in Table 1. Older age (more than 50 years) $(p=0.001)$ and lower educational attainment $(p=0.048)$ were significantly associated with a greater risk of PTSD (Table 1).

The data about the intensity of flood exposure revealed that more than $95 \%$ of the study population had suffered tangible losses to their homes and property. Moreover, $64 \%$ of those surveyed had lost their livelihood in the same year. As the study area is close to the riverbanks, all of the families surveyed were found to have been displaced and shifted to temporary camps, at some point, during the flood-relief operations carried out by the state government. This data, along with the evident loss of life, established that the flood was of sufficiently great intensity.

The loss of a relative $(p=0.011)$, physical injury $(p=$ 0.015 ), and affliction with a physical illness at the time $(p=0.004)$ were predictors that were significantly associated with the symptoms of PTSD (Table 2).

It was noted that $65 \%$ of those surveyed had a high intensity of flood-exposure and $35 \%$ had a low intensity of exposure. A higher intensity of flood exposure was found to be significantly associated with a greater incidence of PTSD.

\section{DISCUSSION}

In our study, the prevalence of PTSD in a rural population in Kerala, following floods, was determined to be $22 \%$. Hollifield et al. had obtained a similar prevalence in a study conducted in Sri Lanka. ${ }^{10}$ This figure is also comparable to the prevalence noted in Gujarat following flash floods in Surat in 2006 (23.3\%). ${ }^{11}$ However, a study conducted in Ladakh following flash floods in 2010 identified only two cases of PTSD among 318 survivors who were interviewed. As $86.2 \%$ of the sample in the above study comprised of Tibetan refugees, it was postulated that the temperament of the Tibetan people, their social background, and their attitudes to life's stressors, may have played a protective role. ${ }^{12}$ Hence, cultural factors contribute to the prevalence of PTSD in communities that have been 
Table 2. Association of variables of the intensity of flood exposure with PTSD in the study population

\begin{tabular}{|c|c|c|c|c|c|}
\hline Variable & & PTSD present & PTSD absent & Chi-square & p-value \\
\hline \multirow{2}{*}{ Loss of relative } & Yes & $4(13.6 \%)$ & $1(1.3 \%)$ & \multirow[b]{2}{*}{ - } & \multirow{2}{*}{$0.011^{* \#}$} \\
\hline & No & $18(86.3 \%)$ & $77(98.7 \%)$ & & \\
\hline \multirow{2}{*}{ Injury to body } & Yes & $7(31.8 \%)$ & $9(11.5 \%)$ & \multirow{2}{*}{5.942} & \multirow{2}{*}{$0.015^{\#}$} \\
\hline & No & $15(68.2 \%)$ & $69(88.5 \%)$ & & \\
\hline \multirow{2}{*}{ Physical Illness } & Yes & $18(81.8 \%)$ & $37(47.4 \%)$ & \multirow{2}{*}{7.234} & \multirow{2}{*}{$0.004^{\#}$} \\
\hline & No & $4(18.2 \%)$ & $41(52.6 \%)$ & & \\
\hline \multirow{2}{*}{ Loss of property } & Yes & $21(95.5 \%)$ & $7(94.9 \%)$ & \multirow[b]{2}{*}{ - } & \multirow{2}{*}{$0.654^{*}$} \\
\hline & No & $1(4.5 \%)$ & $4(5.1 \%)$ & & \\
\hline \multirow{2}{*}{ Loss of Livelihood } & Yes & $15(68.2 \%)$ & $49(58.9 \%)$ & \multirow{2}{*}{0.082} & \multirow{2}{*}{0.644} \\
\hline & No & $7(31.8 \%)$ & $29(41.1 \%)$ & & \\
\hline \multirow{2}{*}{ Loss of Livestock } & Yes & $10(45.5 \%)$ & $25(32.1 \%)$ & \multirow{2}{*}{1.861} & \multirow{2}{*}{0.173} \\
\hline & No & $12(54.5 \%)$ & $53(67.9 \%)$ & & \\
\hline \multirow{2}{*}{ Damage to house } & Yes & $21(95.9 \%)$ & $74(94.9 \%)$ & \multirow[b]{2}{*}{-} & \multirow{2}{*}{$0.351^{*}$} \\
\hline & No & $1(4.5 \%)$ & $4(5.1 \%)$ & & \\
\hline \multirow{2}{*}{ Displacement } & Yes & $20(90.9 \%)$ & $72(92.3 \%)$ & \multirow[b]{2}{*}{ - } & \multirow{2}{*}{$0.673^{*}$} \\
\hline & No & $2(9.1 \%)$ & $6(7.7 \%)$ & & \\
\hline \multirow{2}{*}{ Involvement in rescue } & Yes & $7(31.8 \%)$ & $22(28.2 \%)$ & \multirow{2}{*}{0.242} & \multirow{2}{*}{0.622} \\
\hline & No & $15(68.2 \%)$ & $56(71.8 \%)$ & & \\
\hline \multirow{2}{*}{ Financial loss } & Yes & $21(95.5 \%)$ & $75(96.2 \%)$ & \multirow[b]{2}{*}{ - } & \multirow{2}{*}{$0.617^{*}$} \\
\hline & No & $1(4.5 \%)$ & $3(3.8 \%)$ & & \\
\hline The intensity of flood exposure $(>6$ & High & $20(90.9 \%)$ & $45(57.7 \%)$ & - & $0.004^{* \#}$ \\
\hline stressors) & Low & $2(9.1 \%)$ & $33(42.3 \%)$ & & \\
\hline
\end{tabular}

* Fisher's exact test, ${ }^{\#} \mathrm{P}<0.05$, PTSD: Posttraumatic Stress Disorder

exposed to traumatic events like natural disasters.

Next, we evaluated the extent to which sociodemographic variables contributed to PTSD symptoms in the study population. A study by Norris et al. determined that increased age could have varying impacts on PTSD symptoms depending on the cultural context. ${ }^{13}$ In a similar vein, although there is no consensus on the effect of age on the development of PTSD, our study revealed that older age was associated with a greater incidence of PTSD. This may be attributed to age-related stressors such as sensory impairment, cognitive decline, physical illness, retirement, financial constraints, bereavement, loss of social support, and role changes, that make it difficult to cope with the memories of the trauma. Existing literature supports the understanding that females are more prone to suffer PTSD. 9, 14, 15 This has been explained by their greater exposure to high-impact trauma (such as sexual trauma), use of coping strategies that are more emotion-focused than problem-focused, and biological phenomena such as a more sensitized hypothalamus-pituitary axis. Although the proportion of females who have PTSD was found to be higher when compared to males in our study, this finding was not found to be statistically significant. This may be attributed to the disproportionate number of female respondents interviewed, as most of the male family members were at work during the hours of the survey. We also noted that a lower level of educational attainment was significantly associated with PTSD. A nationwide epidemiological study undertaken in the United States of America on the prevalence and sociodemographic correlates of PTSD was in concurrence with this finding, as was a meta-analysis conducted by Brewin et al. regarding the risk factors for PTSD in adults exposed to trauma. ${ }^{16,17}$ This may be explained by the better economic status and greater access to healthcare and information that is generally available to those with a higher degree of educational attainment, that, in turn, can play a role in protecting against the development of PTSD. ${ }^{18}$

We also attempted to determine the intensity of flood exposure among the affected people. A study conducted by Neelofar et al. that focused on the intensity of exposure to a natural disaster in the state of Jammu \& Kashmir established that $100 \%$ of those surveyed had 
suffered a loss of property and possessions. ${ }^{19}$ The figure of $95 \%$ obtained in our study is found to be comparable. Similarly, whereas the proportion of persons who sustained a loss of livelihood was $50 \%$ in the study mentioned above, we found that $64 \%$ of the floodaffected population suffered similar losses. These similarities in findings reflect the comparable severities of the stressful event in both studies and reveal that the floods in Kerala constituted an event of considerable stress in the study population.

We tested the hypothesis that the intensity of flood exposure is related to PTSD symptoms in the study population. We determined that a higher intensity of flood exposure is associated with a greater prevalence of PTSD, and this was found to be statistically significant.

Finally, we were able to identify certain flood-related factors such as the loss of a relative, physical injury, and affliction with a physical illness, that were present in several subjects and could, in turn, possibly be risk factors for the development of PTSD in the future. This has been previously demonstrated in a follow-up study that spanned 17 years, that was undertaken to assess PTSD symptoms in survivors of the Dongting Lake flood in China. ${ }^{9}$

Our study had a few limitations. The study sample had a preponderance of female respondents, presumably because the data collection was carried out during the hours in which the male members of the family were at work. Pre-existing psychiatric disorders were ruled out based on self-report. Data regarding the intensity of exposure to floods in 2018 was obtained after a gap of one year and may have been subject to some recall bias. However, previous studies have reliably documented symptoms of PTSD up to 21 months after the natural disaster. ${ }^{10}$ Therefore, this may not necessarily preclude the drawing of robust conclusions from the primary data. Finally, the cross-sectional nature of the study meant that causal inferences about the subject matter could not be conclusively drawn.

Our study has several implications for the implementation of appropriate policies, to safeguard the psychological wellbeing of the native population following similar floods in the future. Our research demonstrates the need to conduct post-disaster mental health screening for planning intervention strategies to mitigate the resulting psychological fallout of exposure to floods. Medical personnel must educate the population about the symptoms of PTSD so that they can seek the necessary help. People who have PTSD need a timely referral to psychiatric services for the management of persisting symptoms. There is also much that can be done, at a community level, to alleviate the symptoms of PTSD in the affected populations. For instance, a model of psychosocial care that was implemented by mental health teams from the National Institute of Mental Health and Neuro-Sciences (NIMHANS) in Bengaluru, in women survivors of the tsunami that struck Indian coastal communities in 2004, was found to be effective in reducing psychological distress. ${ }^{20}$ Hence, early diagnosis, combined with the appropriate pharmacological, psychological and psychosocial interventions, are imperative to manage PTSD in communities that are ravaged by such natural calamities. Moreover, as meteorological data suggest that floods may become a yearly phenomenon in Kerala, there is scope for further studies to determine whether previous exposure worsens mental health issues due to repetitive stress, or conversely if it improves resilience thereby proving to be a protective factor.

To conclude, our study established that $22 \%$ of the population suffered from symptoms of PTSD following floods. Several risk factors for the development of PTSD were identified. A greater intensity of exposure to a disaster was found to precipitate more severe mental health issues in the affected population. Finally, our study reveals that there is a pressing need for early recognition and management of the psychological aftermath of floods and other natural disasters.

\section{Financial support and sponsorship}

None.

\section{Conflict of interest}

None declared.

\section{Acknowledgement}

The authors would like to place on record their gratitude to the undergraduate batch of 2017 (Batch C) for their enthusiastic involvement in the data collection

\section{REFERENCES}

1. World Health Organization (WHO). Disasters and definitions [Internet]. 2002. [cited 2019 September 16]. Available from: http://apps.who.int/disasters/repo/7656.pdf

2. Norris F, Friedman M, Watson P, Byrne C, Diaz E, Kaniasty K. 60,000 Disaster Victims Speak: Part I. An Empirical Review of the Empirical Literature, 1981- 
2001. Psychiatry: Interpersonal and Biological Processes 2002; 65:207-39.

3. Diagnostic and statistical manual of mental disorders. Arlington, VA: American Psychiatric Association; 2017.

4. Kerala rains: Toll reaches 125,17 still missing. The Hindu. Thiruvanathapuram. 2019 Aug 21. Available from: https://www.thehindu.com/news/national/kerala/keralarains-toll-reaches-125-17-still-missing/article29212558.ece

5. Ashok V, Premarajan KC, Rajkumar R, Naik B. Mental health status of flood-affected adults in rural Tamil Nadu: A cross-sectional study. CHRISMED J Health Res 2019; 6:97.

6. Weathers FW, Litz BT, Keane TM, Palmieri PA, Marx BP, Schnurr PP. The PTSD Checklist for DSM-5 (PCL-5). [Internet]. 2013. Available from: https://www.ptsd.va.gov/professional/assessment/adult-sr/ptsdchecklist.asp

7. Nayak S, Kamath A, Gupta K, Roy A, Roy S, Chatterjee A. Post-traumatic stress disorder among patients with oral and maxillofacial trauma in a South Indian population. Spec Care Dentist 2019; 39:399-405.

8. Wortmann JH, Jordan AH, Weathers FW, Resick PA, Dondanville KA, Hall-Clark B, et al. Psychometric analysis of the PTSD Checklist-5 (PCL-5) among treatment-seeking military service members. Psychol Assess 2016; 28:1392-403.

9. Dai W, Kaminga A, Tan H, Wang J, Lai Z, Wu X, et al. Comorbidity of post-traumatic stress disorder and anxiety in flood survivors. Medicine 2017; 96:e7994.

10. Hollifield M, Hewage C, Gunawardena C, Kodituwakku P, Bopagoda K, Weerarathnege K. Symptoms and coping in Sri Lanka 20-21 months after the 2004 tsunami. Br J Psychiatry 2008; 192:39-44.

11. Patel FM, Oswal RM, Meheta RY. Post-traumatic Stress Disorder in Adult Victims of 2006 Flood in Surat, Gujarat. J Res Med Den Sci 2015; 3:303-6.

12. Ishikawa M, Yamamoto N, Yamanaka G, Suwa K,
Nakajima S, Hozo R, et al. Disaster-related psychiatric disorders among survivors of flooding in Ladakh, India. Int J Soc Psychiatry 2013; 59:468-73.

13. Norris F, Murphy A, Baker C, Perilla J, Rodriguez F, Rodriguez J. Epidemiology of Trauma and Posttraumatic Stress Disorder in Mexico. J Abnorm Psychol 2003; 112:646-56.

14. Rajkumar A, Mohan T, Tharyan P. Lessons from the 2004 Asian tsunami: Epidemiological and nosological debates in the diagnosis of post-traumatic stress disorder in non-Western post-disaster communities. Int J Soc Psychiatry2011; 59:123-9.

15. Olff M. Sex and gender differences in post-traumatic stress disorder: an update. Eur. J. Psychotraumatol 2017; 8:1351204.

16. Goldstein R, Smith S, Chou S, Saha T, Jung J, Zhang H et al. The epidemiology of DSM-5 post-traumatic stress disorder in the United States: results from the National Epidemiologic Survey on Alcohol and Related Conditions-III. Soc Psychiatry Psychiatr Epidemiol 2016; 51:1137-48.

17. Brewin CR, Andrews B, Valentine JD. Meta-analysis of risk factors for post-traumatic stress disorder in traumaexposed adults. J Consult Clin Psychol 2000; 68:748-66.

18. Li L, Reinhardt JD, Van Dyke C, Wang H, Liu M, Yamamoto A, et al. Prevalence and risk factors of posttraumatic stress disorder among elderly survivors six months after the 2008 Wenchuan earthquake in China. BMC Psychiatry 2020; 20(1).

19. Neelofar MR, Qadri J, Bhat RA. Socio-economic and Health impacts of Floods in a Trans-Himalayan Ecosystem. Journal of Geography \& Natural Disasters 2018; 8:1-4.

20. Becker SM. Psychosocial care for women survivors of the tsunami disaster in India. Am J Public Health, 2009; 99:654-8. 